\title{
JOURNAL POLICIES
}

\section{Open Access Policy}

In order to ensure maximum reach of Indian Journal of Science and Technology

contents, we have adopted the open access policy, meaning that;

- All the articles published in Indian Journal of Science and Technology are made freely accessible online immediately after publication in an easily readable format, without any subscription or registration barrier.

- All the published articles are licensed under a Creative Commons license. Articles can be shared and adapted, provided the attribution for the work is given

\section{Peer-review Policy}

All the manuscripts submitted to Indian Journal of Science and Technology will be subjected to double blinded peer review process;

- The manuscript will be reviewed by two suitable experts in respective subject area.

- The reports of both the reviewers will be considered while deciding on acceptance/revision or rejection of a manuscript.

- Editor-In-Chief will make the final decision, based on reviewer's comments.

- Editor-In-Chief can ask one or more of the advisory board members for their suggestions upon a manuscript, before making the final decision.

- Associate editor and review editors provide the administrative support to maintain the integrity of peer review process.

- In case, authors challenge editor's negative decision with suitable arguments, the manuscript can be sent to one more reviewer and the final decision will be made based upon his recommendations.

\section{Licensing Policy}

To fully realize the potential of open access to research literature, barriers to reuse need to be removed. The Creative Commons (CC) licenses have emerged as an effective legal instrument to achieve this.

Instead of transferring rights exclusively to publishers (the approach usually followed in subscription publishing), authors grant a non-exclusive license to the publisher to distribute the work, and all users and readers are granted rights to reuse the work.

CC-BY allows for unrestricted reuse of content, subject only to the requirement that the source work is appropriately attributed. The CC-BY license thereby requires that authors are given appropriate credit for their work, as explained in a recent post from Creative Commons (http://wiki.creativecommons.org/BIS committee UK OA Policy).

\section{Archiving Policy}

This journal utilizes the AWS system to create permanent archives of the journal for purposes of preservation and restoration.

\section{PUBLICATION ETHICS}

The Indian Journal of Science and Technology is an electronic Double Blind peer reviewed journal upholding the highest standards. Articles not in accordance with publication ethics and malpractices will be removed from publication if detected at any time. Plagiarism and research fabrication such as making up of data, manipulation of existing data, tables etc. and ethical clearance on the use of humans or animals for the study will also be checked. The journal reserves the right to use plagiarism detecting software to screen submitted papers at any time and suspected plagiarism or duplicate publishing will be reported immediately. 


\section{Authors Responsibility}

They must ensure that

- Their work is original

- Must not have been published elsewhere

- Other authors, contributors or sources should be appropriately credited

- They are responsible for language editing before submission

- Their work has not been copied or plagiarized in whole or part from any other work

- The financial support and conflict of interest for the project / research work if any should be disclosed

- They are obliged to notify the editor if any error or inaccuracy is discovered and cooperate with the editor to correct the same

Articles should be submitted using online procedures. Simultaneous publication in more than one publication is a breach of publication ethics.

Committee on Publication Ethics (COPE) during the 2nd World Conference on Research Integrity in Singapore in 2010 has developed the below mentioned guidelines. Sciresol Journals, as a publisher follows COPE, WAME and has adopted COPE's best practice guidelines for dealing with ethical issues in a journal. The Journal Members (Advisory Board, editors and the journal manager) have consented to adopt the COPE as it meets the purpose and objective of the Journal.

The following is a summary of COPE's international standards for authors of scholarly research publications and describes responsible research reporting practice. The comprehensive guidelines can be downloaded here

- The research being reported should have been conducted in an ethical and responsible manner and should comply with all relevant legislation.

- Researchers should present their results clearly, honestly, and without fabrication, falsification or inappropriate data manipulation.

- Researchers should strive to describe their methods clearly and unambiguously so that their findings can be confirmed by others.

- Researchers should adhere to publication requirements that submitted work is original, is not plagiarized, and has not been published elsewhere.

- Authors should take collective responsibility for submitted and published work.

- The authorship of research publications should accurately reflect individuals' contributions to the work and its reporting.

- Funding sources and relevant conflicts of interest should be disclosed.

\section{Editor's Responsibility}

They must ensure that

- The submitted manuscript undergoes Double - blind peer review before publishing

- They will strive to prevent any conflict of interest between the author and editorial and review personnel

- All the information related to the submitted manuscript is kept confidential prior to publishing 


\section{Reviewers Responsibility}

They must ensure that

- Reviews of the manuscript is completed and provides suitable comments for improvement

- Promptness in notifying the editor about his inability to review the manuscript

- Maintains confidentiality about the manuscript obtained for review, by not discussing with others

- Standards of Objectivity preserved by reviewing the manuscripts objectively with clear views and supporting arguments and without any personal criticism

- Acknowledgement of Sources

- All References not cited by author should be removed. All citations should be accompanied with any previously reported observation, derivation or argument.

- The editors should be intimated for any overlap of the reviewed manuscript with any other published paper.

- Disclosures and Conflict of Interest-manuscripts having conflict of interest resulting from competitive, collaborative or any other relationships or connections with institutions connected to the paper will not be considered.

In case, plagiarism is detected during review/editorial process, such manuscript(s) will be rejected immediately and we can also consider other steps depending upon the seriousness of the case. If the plagiarism is proven after publication, such manuscript(s) will be removed from our website and appropriate announcement will be placed in this regards.

Further, Indian Journal of Science and Technology can bring such instances in notice of author's funding agencies, author's institutes (where they work) and to the original authors whose work has been plagiarized. Please report the plagiarism to indjst@gmail.com

\section{V Manuscript Withdrawal Policy}

Authors must abide by these policies after submission of their manuscript.

- Authors must provide their consent to publish their manuscript prior to peerreview process. Withdrawing an already confirmed manuscript after it has been accepted would attract a minimal article handling charge.

- If the author withdraws the article after acceptance of the manuscript and payment has also been made, there will be NO REFUND of the Article Processing Charge (APC) already paid.

- If a Manuscript is withdrawn over indexing issues, NO REFUND will be made.

\section{VWaiver Policy}

- Indian Journal of Science and Technology may grant the partial/full waiver in article processing charges to those authors who are unable to pay the APCs due to financial crisis.

- Only the authors from low income countries can apply for waiver.

- Waiver is applicable for one article per year for each submitting author.

Please send your waiver requests to indjst@gmail.com 


\section{Disclaimer}

The author(s) of each article appearing in this Journal is/are solely responsible for the content thereof; neither the Indian Journal of Science and Technology nor its editors or publisher or anyone else involved in creating, producing or distribution assumes any liability or responsibility for the accuracy, completeness, or usefulness of any information provided in the Journal, nor shall they be liable for any direct, indirect, incidental, special, consequential or punitive damages arising out of the use of Indian Journal of Science and Technology.

\section{Plagiarism}

For every Journal, the peer review process is at the heart of the success of publishing. As part of our commitment to the protection and enhancement of the peer review process, The Indian Journal of Science and Technology would like to ensure that all published articles are within the accepted level of plagiarism. The Journal uses the very well and widely accepted Plagiarism Detection tool, iThenticate. All submitted Manuscripts are first subjected to Plagiarism check and then the Publishing cycle begins.

In case, plagiarism is detected during review/editorial process, such manuscript(s) will be rejected immediately and we can also consider other steps depending upon the seriousness of the case. If the plagiarism is proven after publication, such manuscript(s) will be removed from our website and appropriate announcement will be placed in this regards. Further, "Indian Journal of Science and Technology" can bring such instances in notice of author's funding agencies, author's institutes (where they work) and to the original authors whose work has been plagiarized. Please report the plagiarism to indist@gmail.com

\section{Article Retraction}

Editor's decision is the decisive factorforall scholarly publications. However, this decision is based on Editorial Policies - which includes plagiarism, copyright etc. It becomes important to retain the Published articles as it is - without any alterations. However, owing to certain circumstances, a published article may at times be retracted, removed or may require a change.

Retraction could be due to:

- Plagiarism

- Bogus Authorship

- Fraudulent Data

- Correction in Publication

Standards for Article Retraction at Sciresol Journals are:

The article PDF will remain available with the watermark "Retracted" available on it. Only in case of legal/controversial/incorrect PDF, they will be replaced or removed completely from the website with a note. 